\title{
De la clase social a la estructura de unidades domésticas en el agro. El continuo campesino-proletario y una propuesta para su análisis
}

\author{
From social class to the structure of domestic units in agriculture. The continuous peasant-proletarian and a \\ proposal for its analysis
}

Pablo Cuevas Valdés

Universidad Católica de Temuco, Chile

pcuevas@uct.cl

\section{RESUMEN:}

El artículo se inserta en la problemática de las transformaciones del mundo agrario latinoamericano y de la diferenciación de las clases sociales del agro, reeditando discusiones acerca del complejo campesino-proletario, en el contexto de las actuales economías agroexportadoras. El objetivo del artículo es plantear una propuesta teórico-metodológica para estudiar la estructura de unidades domésticas agropecuarias, a partir de una operacionalización de esta noción en relación al concepto clase. Se concluye con el planteamiento de una tipología de UDs, que permite caracterizar las estructuras de reproducción de la fuerza de trabajo a partir de las fuentes de origen de sus ingresos.

Palabras Clave: Unidades domésticas, Clase social, Trabajadores agropecuarios, Campesinado, Tipología, Chile.

\section{ABSTRACT:}

The article is inserted in the problematic of the transformations of the Latin American agrarian world and of the differentiation of the social classes of agriculture, reissuing discussions about the peasant-proletarian complex, in the context of the current agroexporting economies. The objective of the article is to propose a theoretical-methodological proposal to study the structure of agricultural domestic units (DUs), starting from an operationalization of this notion in relation to the class concept. It is concluded with the proposal of a typology of DUs, which allows to characterize the structures of reproduction of the work force from the sources of origin of its income.

KEYwORDs: Domestic units, Social class, Agricultural workers, Peasantry, Typology, Chile.

\section{INTRODUCCIÓN}

Durante el tercer cuarto del siglo XX, el mundo agrario concentraba la atención de una parte significativa de la academia latinoamericana. Grandes debates referidos a la estructura agraria, tipos de productores, sus interacciones, y los procesos de modernización tenían lugar en un bullido espacio académico. El desarrollismo prevaleciente favorecía la búsqueda de herramientas para modernizar e insertar sistemas productivos agrarios "atrasados" en un "capitalismo moderno", lo que propiciaba un debate teóricamente muy heterogéneo.

Con el posterior cese del ímpetu desarrollista y ante la llegada de una nueva fase liberalizadora en el último cuarto del siglo XX, estas discusiones perdieron su vigencia, de manera paralela al avance de nuevas posiciones teóricas en las ciencias sociales. Desde la nueva doctrina económica, poco importaban las cuestiones de la estructura productiva; sólo quedaba no "interferir" con el rol del mercado, ahora crecientemente mundializado. La sociología y la antropología secundaron en los hechos el mandato de la nueva estrategia modernizadora, y en el contexto de la hegemonía de análisis, más particulares y que desautorizaban perspectivas estructurales y totalizadoras, privilegiaron otro tipo de problemáticas. Salvo excepciones, el ambiente académico latinoamericano de las últimas tres décadas se ha caracterizado por un relativo desinterés respecto de problemas referentes al mundo agrario y de las particularidades de la estructura social y agraria latinoamericana.

\section{Recepción: 17 de febrero de 2019 | Aceptación: 05 de julio de 2019 | Publicación: 15 de agosto de 2019}


El derrotero que siguió la teoría social, luego de las grandes transformaciones acontecidas en el capitalismo mundial desde el último cuarto del siglo XX, ha estado igualmente lejos de favorecer perspectivas de análisis y ejes temáticos que rompan con la tendencia a disolver las "fronteras" disciplinares. La compenetración de los problemas económicos, políticos, sociales y culturales, pese a su larga tradición de estudios desde las corrientes teóricas materialistas, ha estado lejos de figurar entre los ejes de mayor visibilidad en las ciencias sociales de las últimas décadas. A contracorriente de lo anterior, el presente artículo parte desde la puesta en relieve de la necesidad actual de estudiar de manera profunda aspectos como la reproducción de la fuerza de trabajo en el agro latinoamericano. Allí son relevantes conceptos cuyo dominio disciplinar es liminal en los marcos teóricos dominantes, como son clase social y unidad doméstica, que articulan dentro sí dimensiones económicas, antropológicas y sociológicas.

El presente artículo tiene por objetivo presentar al lector una propuesta teórico-metodológica para estudiar la estructura de UDs agropecuarias, a partir de una discusión que operacionaliza esta noción en relación al concepto clase social, y a la lógica teórica detrás de éste. Como resultado de lo anterior, se presenta una propuesta de tipología de unidades domésticas -cuyo objetivo es caracterizar una o varias estructuras de reproducción de la fuerza de trabajo-, entendida como la expresión general del peso y proporción de diferentes maneras en que las UDs resuelven su reproducción, a partir de la forma en que esos núcleos componen su ingreso (las fuentes de éstos), organizando esas posibilidades en tipos. De esta manera se busca identificar UDs que son clasificables en un continuo heterogéneo de posibilidades entre campesinas, proletarias y capitalistas. Esta tipología, si bien es principalmente descriptiva, pretende captar el tipo de relaciones sociales dominantes que establecen esas unidades con la producción.

La potencial aplicación y comparación de esta tipología permite relacionar determinados perfiles de composición de ingreso a diferentes características del mercado laboral y los salarios, y observar si determinados perfiles son asociables a determinadas configuraciones del mercado laboral, en espacios diferenciados. $^{1}$

En lo concreto, la propuesta consiste en un "modelo" que -tras su eventual aplicación y comparación en diferentes estructuras agrarias- permite perseguir la hipótesis de que una estructura de unidades domésticas, que tiene elevada presencia de fuentes de ingreso diferentes al salario, se asociará a un mercado de trabajo silvoagropecuario con tendencia a tener salarios comparativamente bajos (Cuevas, 2017). Esta hipótesis representa una continuidad -desde la arista reproductiva, en lugar de laproductiva- de la clásica hipótesis de que una mayor presencia de campesinos en una estructura agraria tiende a favorecer un mercado de trabajo con salarios menores respecto a los de otras estructuras en las que éstos no están tan presentes. ${ }^{2}$ Esta hipótesis no es abordada empíricamente en el presente artículo.

El texto se estructura desde lo abstracto a lo concreto. Primero, se desarrolla una reflexión que comienza con un posicionamiento crítico frente al uso de la idea de nueva ruralidad, para luego recuperar una perspectiva teórica que pone de manifiesto la necesidad de estudiar lo social en relación a aquello que lo constituye, es decir, las relaciones sociales. En esta línea, el texto continúa con el concepto de clase social, y el problema de la reproducción de los grupos sociales, asociados a medios de producción y sectores productivos; problematiza tanto su necesaria concretización, y, desde allí, su relación con el concepto de UD y la composición múltiple -y variada- del ingreso en estas unidades. ${ }^{3}$ El problema de un continuo heterogéneo de posibilidades entre unidades campesinas, proletarias y capitalistas conduce a una discusión respecto de la noción de campesinado y a su manera de entender formas transicionales del mismo. Por último, el texto expone la tipología de UDs. 


\section{LA “NUEVA RURALIDAD”: ¿Y LOS VIEJOS PROBLEMAS?}

Que las características de la ruralidad de las primeras décadas del siglo XXI difieren de las de la ruralidad de la posguerra, es algo bastante evidente. Sin embargo, permitir que el nivel de lo descriptivo limite las interrogantes más abstractas es un error y una tendencia clara en el pensamiento social reciente, que aquí intentaremos evitar. En las siguientes páginas propondremos un abordaje de la cuestión agraria que toma cierta distancia de las tendencias que predominaron en las últimas décadas del siglo XX y las primeras del actual.

Yes que, en el marco de las nuevas perspectivas, la noción de ruralidad se ha puesto en discusión a propósito de una serie de cambios históricos concretos que han ocurrido en el mundo rural, tanto en países centrales como dependientes. Estas nuevas hegemonías teóricas han contribuido a generar un particular acercamiento desde las ciencias sociales a la ruralidad. Como bien lo señala Kay (2007), el culturalismo, relativismo, particularismo e individualismo, en el marco la influencia posmoderna aumentaron su predominio, mientras que el marxismo, con su enfoque totalizador, perdió cierta preponderancia entre los nuevos ruralistas. Es en este contexto que tanto en los países centrales como en Latinoamérica comienza a hablarse de "nueva ruralidad". Este "concepto", en un principio, hacía referencia a un conjunto de propuestas teóricoconceptuales que, en Europa y EEUU, desde las décadas de 1970 y 1980 tienden a cuestionar o a poner en duda la pertinencia de una realidad definible bajo el concepto de "ruralidad". ${ }^{4}$ Su origen se encuentra en el trabajo de diversos académicos, fundamentalmente ingleses, franceses y norteamericanos, que ante la realidad observable en sus países comenzaron a hacer hincapié en los profundos cambios sufridos por los antaño incuestionables espacios rurales. ${ }^{5}$ Entre las transformaciones aludidas se puede mencionar: poblaciones urbanas se trasladan al campo, donde se transforman en residentes rurales con trabajos urbanos no agrícolas, o que poseen un trabajo no agrícola en sede rural, o que deciden dedicarse a ocupaciones ligadas a la tierra, inspirados en una "filosofía revitalizadora de naturaleza" (Ratier, 2002).

A partir de una visión teórica que fractura las relaciones sociales, no es sorprendente que se esencialice toda clase de procesos derivados de cambios nacionales e internacionales en la división internacional del trabajo, y, con ello, en los patrones de reproducción del capital; ${ }^{6}$ se busca en el dato y no en las relaciones socialesel sentido de esos cambios. Blanca Rubio (2002) destaca el hecho de que estos cambios señalados por los "nuevos ruralistas" de los países centrales son consecuencia de la crisis del modelo productivo anterior y de la consecuente modificación en la política agrícola de los países centrales, lo que trajo consigo la marginación de las actividades productivas agrícolas, y que derivó en cambios como, por ejemplo, el declive de los ingresos de origen rural.

En América Latina, el concepto ha tenido tanto detractores como defensores, pero, en general, la palabra se ha convertido en un "concepto paraguas", utilizado para referirse a cualquier nuevo desarrollo rural (Kay, 2009). A grandes rasgos, se puede distinguir entre quienes aceptan la existencia de una "nueva ruralidad" en el continente (enfoque de la nueva ruralidad), y quienes la niegan y señalan que aquello que la identifica es el producto de la imposición de las políticas neoliberales, es decir, "nueva ruralidad" sólo como ruralidad propia del contexto económico neoliberal. Nuestra postura respecto a la "nueva ruralidad" es escéptica respecto de la necesidad del concepto, su carga posmoderna y su pretensión "vanguardista”, y crítica respecto del planteamiento concreto.

$\mathrm{Al}$ restringir el enfoque hacia el ámbito espacial, la perspectiva de la "nueva ruralidad" deja de lado la cuestión de las relaciones de producción. Con ello, el enfoque esencializa sectores de la economía que, de ninguna maneradejan de existir. Cambia, por un lado, el espacio geográfico en que se producen algunas de las mercancías en la red global de intercambios (por ejemplo, el mexicano consume maíz estadounidense y el estadounidense tomates mexicanos), y, por otro lado, cambia también el carácter de la relación entre esos 
sectores, para reconfigurarse, por ejemplo, en un tipo de vínculo entre industria y agricultura (Rubio, 2001, 2002). ${ }^{7}$

En el presente artículo se recupera una visión teórica que pone el acento en las relaciones sociales, la totalidad social, y que es crítica de la manera en que se ontologizan las fronteras disciplinares (Osorio, 2012, 2014, 2016; Pérez Soto, 2008). En este sentido, pensamos que es el espacio el que es definido por las relaciones sociales que allí predominan y no al revés. Así, la ruralidad es aquel espacio en que las relaciones sociales se organizan mayoritariamente - no exclusivamente- para producir aquello que se consume principalmente en las ciudades -dentro o fuera de un país- y que comúnmente no se puede producir en ellas (de manera masiva). Más que la frontera espacial, lo central en esta noción es la división social del trabajo, fenómeno que históricamente crea a la ciudad y su contracara: el mundo rural.

Ante los objetivos de esta propuesta, antes que en una "nueva ruralidad", resulta más interesante poner atención en aquello que permanece en el mundo rural, en los viejos problemas que continúan siendo actuales. Las transformaciones recientes no dejan de ser de todo interés, sin embargo, su estudio no debe ser a costa del abandono de realidades que caracterizan la ruralidad latinoamericana, como la explotación y la precariedad del trabajo. Así como lo concreto se estudia en relación a lo abstracto, los elementos nuevos se estudian en relación a aquellos que permanecen. Es en este sentido que en las próximas líneas se discute una propuesta que atiende a esa dialéctica abstracto-concreta, y que presenta una propuesta para el estudio de estas "permanencias". De esta manera, se pone a discusión la noción abstracta de clase social y su relación con la reproducción de la fuerza de trabajo, donde aparece el problema de la identificación de UDs que pueden reproducirse con fuentes de ingreso múltiple, asociadas a diferentes medios de producción, lo que da lugar a una tipología UDs que organiza esas posibilidades de vinculación al sistema productivo en un continuo campesino-proletario-empresarial.

\section{RELACIONES Y GRUPOS SOCIALES: DE LA CLASE SOCIAL A LAS UNIDADES DOMÉSTICAS}

La vida social no puede explicarse por el comportamiento individual, "la sociedad no es una simple suma de individuos cuya suerte social es fundamentalmente un problema individual, sino, por el contrario, resultado de un entramado de relaciones que liga y amarra la suerte de unos conglomerados sociales con otros" (Osorio, 2009b, p. 98). En ese sentido, la clase social es, y no ha dejado de ser, una categoría fundamental del análisis social. Marx reconoce tres clases sociales: "Son tres los grandes grupos sociales, cuyos componentes, los individuos que las forman, viven respectivamente de salario, ganancia y renta de la tierra, de la valorización de su fuerza de trabajo, su capital y su propiedad de la tierra" (Marx, 1986, p. 1124). Sin embargo, la existencia exclusiva de éstas, refiere al nivel de abstracción más elevado: ${ }^{8}$ al delmodo de producción. ${ }^{9}$ La descripción abstracta del modo de producción es una dimensión de la realidad concreta, fundamental para comprender sus tendencias generales a partir de la selección de aquellos elementos que rigen su lógica general, pero, en tanto concreta, ésta es a su vez síntesis de otras determinaciones, que deben ser incorporadas. Por lo tanto, al acercarnos a una realidad más concreta, como es por ejemplo el mundo agrario latinoamericano, es necesario incorporar sus determinaciones históricas particulares, es decir, complejizar el análisis.

Lo esencial del concepto de clase social, a diferencia de la idea de estratos sociales, es que opera identificando grupos sociales a partir de la manera en la que éstos se vinculan al funcionamiento estructural de la sociedad y su reproducción material (Osorio, 2001). Esto no implica desconocer que existen en la sociedad otros agrupamientos sociales, muchos de ellos, relevantes para explicar diferentes dinámicas. Se trata más bien de "subrayar aquellos agrupamientos y relaciones que para los fines de la comprensión de la dinámica societal y sus movimientos, ocupan un lugar fundamental" (Osorio, 2009b, p.100). La presencia de estos agrupamientos sociales no es una simple constatación de la heterogeneidad social, sino que, más bien, expresa características fundamentales de su organización, lo que favorece una mirada del todo social en tanto unidad completa (Osorio, 2001). Esta perspectiva se distingue de la weberiana, de mucha influencia en la actualidad. 
Weber (1964) plantea una propuesta de clasificación de los individuos según determinados atributos, basado en la premisa del individualismo metodológico. A grandes rasgos, se trata de encontrar puntos de corte en un continuo de atributos personales, identificando grupos con cierta homogeneidad interna (Rosati y Donaire, 2012)

El análisis sociológico ha resuelto de diferentes maneras el problema de la concretización de la clase social y de la heterogeneidad en el interior de las clases, al acercarse a su descripción empírica. Una de ellas ha sido una suerte de estratificación interior de las clases identificadas, que combina la lógica marxista y la weberiana, como es el caso de las ampliamente difundidas propuestas de Dahrendorf y la de Goldthorpe (Cantamutto y Costantino, 2014; Atria 2004). Otro camino para resolver el mismo problema fue el de identificar en el criterio estructural -relaciones respecto de la reproducción de la sociedad- criterios de subdivisión de las grandes clases. Destaca allí la propuesta de de Olin Wright (1983) y de Poulantzas (1979), quienes explicaron la estructuración de las clases según su posición en relación con los medios de producción, el control del proceso productivo y la posesión de habilidades escasas (Cantamutto y Costantino, 2014). Por su parte, Osorio (2001) ha considerado criterios de identificación de facciones y sectores, su lugar en la reproducción del capital (sector financiero, productivo, comercial, etc.), la magnitud de los medios de producción, y la proporción en que el grupo se apodera de la riqueza social. Aquí se trata de identificar grupos a partir de una separación objetiva -una "determinación estructural", diría Poulantzas (1979)-, que, de manera independiente al aspecto subjetivo, intersubjetivo e identitario del colectivo, crea sectores de intereses efectivos.

Sin embargo, más allá de la identificación de subgrupos, hay otro problema que no ha sido abordado tan ampliamente. Este es el de la manera en que los sujetos adscriben a estos grupos objetivos. ¿La clase está compuesta por los sujetos individuales? ¿Éstos son la unidad mínima -una suerte de "átomo"- que compone a la clase? ¿Esa posición en el sistema productivo no alude o integra al grupo donde el individuo reproduce diariamente su existencia en forma colectiva, independientemente de la vinculación de los demás miembros de ese grupo con el sistema productivo? Y si ese grupo tiene fuentes múltiples de ingreso, ¿cómo se resuelve una adscripción colectiva?

La idea del sujeto individual, como ente aislado que se relaciona con los demás seres humanos para resolver la producción de su existencia, no deja de ser una abstracción, y, como tal, debe concretizarse a la hora de observarlo en la realidad histórica. El trabajador se vincula a la producción y se subsume al capital, porque se encuentra despojado de medios de producción suficientes como para reproducirse completamente a sí mismo y a su núcleo directo de forma independiente al capital. Es decir, al encontrarse la relación capital-trabajo mediada por el hecho de que se pone en entredicho la existencia del trabajador y su núcleo, dicha relación de producción es indisociablemente una relación de reproducción desde el punto de vista del trabajador. Al reproducirse a diario el trabajador junto a su núcleo, la forma específica en que ese núcleo operó para su reproducción no es exterior a las particularidades que asume la relación capital-trabajo. En otras palabras, la otra "cara de la moneda" de la producción capitalista es una reproducción del trabajo que opera como un problema colectivo del núcleo directo al que pertenece el trabajador. A ese núcleo lo llamamos unidad doméstica (UD), y sostendremos que se trata de una colectividad dinámica, que es verdadero "átomo" -por decirlo de algún modo- de la clase social -en este caso la clase trabajadora- y no el individuo trabajador.

Si bien dentro de la antropología económica, la consideración de la categoría de UD o es nueva, para la economía neoclásica ha sido del todo novedosa. ${ }^{10}$ El concepto de unidad doméstica proviene de la discusión que se efectúa desde la antropología marxista estructuralista de Claude Meillassoux (1998) en 1975, con la propuesta que en 1974 realiza el antropólogo norteamericano Marshall Sahlins (1977), quien introduce al debate sobre las "economías primitivas" el concepto de "modo de producción doméstico". Meillassoux rechaza la propuesta de Sahlins, y desde su análisis de las relaciones sociales de producción concretas plantea esta categoría derivada de la idea de relaciones domésticas de producción y reproducción, pero ya desvinculadas de un modo de producción que las articule. Las relaciones domésticas, surgidas en 
lo que Meillassoux define como la comunidad doméstica, se constituyen como el cimiento sobre el cual se edifican todos los modos de producción históricos, ya que sobre ella descansa un elemento central en la reproducción de éstos: la reproducción de la fuerza de trabajo. De esta forma, la familia -en el capitalismoencarnaría a la comunidad doméstica, desposeída de sus funciones productivas, pero que conserva siempre sus funciones reproductivas. Por su parte, en el capitalismo "subdesarrollado", señala Meillasoux, persisten funciones productivas y no sólo reproductivas en la familia, y éstas se integran funcionalmente a la circulación capitalista. Con posterioridad, el uso del concepto de UD fue profuso en el contexto de los estudios que se desarrollaron respecto del campesinado en países dependientes en las décadas de 1970 y 1980 (Bartra, 2007; Palerm, 2008, entre otros) y sus relaciones con los procesos de acumulación capitalista (Stoler, 1987; Gordillo, 1992), y ha sido fuertemente retomando en el contexto de los estudios de género (Harris, 1986)

En general, existe relativo acuerdo respecto a que una UD es un núcleo humano dentro del cual se suman los ingresos y el trabajo de varios de sus integrantes en función de la reproducción de todos los integrantes del núcleo, dominado en su interior - principalmente- por la lógica de la reciprocidad generalizada (Cuevas, 2017). Más allá de los vínculos sanguíneos, es lo anterior lo que la define, y no la institución de la familia. Amén de estas generalidades, podemos precisar - siguiendo a Balazote et al (1998) - que el uso de esta categoría no puede referirse sino en su contexto histórico-social particular, a partir de la delimitación de las características del proceso productivo, las relaciones sociales de producción y la división del trabajo. Consideramos infructuoso un esfuerzo destinado a determinar las formas en que opera la elección dentro de la unidad doméstica en abstracto, y sin particularizar dichas determinantes.

Más allá de los pormenores de la discusión teórica, lo cierto es que empíricamente la manera en que se combinan las relaciones productivas domesticas con la relación capital-trabajo tiene un efecto importante sobre los salarios, o al menos así lo ha señalado Wallerstein (2004): "parecen existir diferencias bastante espectaculares, según el lugar y el momento, entre los salarios reales de personas que hacen trabajos prácticamente idénticos, con niveles de cualificación prácticamente idénticos" (Wallerstein, 2004, p. 230). El hecho es que donde priman esas UDs, que incorporan una mayor presencia de relaciones productivas domésticas en su reproducción, los salarios son menores que donde priman las proletarias.

De esta manera, lo que propondremos a continuación es una manera de tipificar las unidades domésticas agropecuarias a partir del peso relativo de sus fuentes de ingreso, como son aquellas derivadas de la relación capital trabajo, y aquellas procedentes de las relaciones productivas domésticas, a las que se suman otros ingresos originados en transferencias. Lo que está detrás de cada tipo es un intento de capturar -de manera general- las relaciones dominantes que priman en la forma en que un grupo de UDs se vincula a la división social del trabajo y al sistema productivo, y en cómo resuelven la reproducción de su existencia. Al referir a entes heterogéneos respecto de sus relaciones, se vuelven necesarios criterios de corte que no dejan de ser arbitrarios, pero que pretenden aproximarse a lo que son las relaciones reales que están detrás de los tipos definidos. En otras palabras, se busca -a fin de cuentas y parafraseando a Lenin (1961) - identificar grupos sociales, es decir, agrupamientos de UDs, a partir de su vinculación con el sistema de producción y con respecto a la propiedad de los medios de producción.

Las unidades domésticas que aplican su trabajo en el sector agropecuario pueden combinar en su interior relaciones de producción distintas, y posiciones individuales distintas respecto de medios de producción. Por lo tanto, lo primero es distinguir los extremos del continuo de posibilidades de combinaciones. En un extremo tendremos las relaciones propiamente capitalistas, caracterizadas por la relación capital trabajo, que se cristaliza en unidades domésticas que pueden ser proletarias o capitalistas (en las que no ahondaremos). En otro extremo tenemos a las unidades domésticas en las que priman las relaciones domésticas, donde aparece con fuerza la idea de campesinado o de economía campesina. Partiremos por este último extremo del continuo. 


\section{El CAMPESINADO COMO ClASE DEL CAPITALISMO DEPENDIENTE: DESDE LOS DEBATES CLÁSICOS Y DESARROLLISTAS A UNA NOCIÓN HISTÓRICA}

Desde que se reconoce en el campesinado una dinámica diferente de la de empresas capitalistas agropecuarias, su definición y manera de entenderlo ha estado sujeta a grandes discusiones. La tradición marxista es de las primeras en abordar con profundidad al campesinado, al identificarlo como una clase social caracterizada por estar en posesión de medios de producción y aplicar sobre ellos su propia fuerza de trabajo

Marx no habla de un modo de producción mercantil simple (Bartra, 1974) o modo de producción campesino (Díaz-Polanco, 1988) -como lo hicieron los autores de la corriente estructuralista del marxismo en América Latina entre las décadas de 1960 y 1980, apoyados en la lectura althusseriana de esa categoría-, sus diversas referencias al campesinado lo ubican siempre como una clase social pertenenciente a tros modos de producción. La razón de ello es que la producción campesina por sí sola, no tiene la capacidad, en ausencia de otras relaciones sociales de producción/dominación, de constituir un sistema de acumulación e instituciones estatales Para Marx, la "pequeña economía agraria" integra orgánicamente algunos modos de producción anteriores al capitalismo, y subiste de forma residual cuando la relación capital-trabajo es la hegemónica: "históricamente, esta forma se desarrolla por oposición a la economía agraria y al artesanado independiente" (Marx, 1968, p. 270).

El campesinado no es, por tanto, una clase que defina al modo de produccióncapitalista en el pensamiento de Marx, y pensamos que teorizar a ese nivel de abstracción su existencia y funcionalidad deriva en una incomprensión -muy frecuente- del método de concretización progresiva propio del cuerpo teórico del Marxismo. ${ }^{11}$ Sin embargo, en los niveles de abstracción menores al del modo de producción, es claramente necesario dar cuenta de su existencia y articulación con las formas históricas que va asumiendo el ciclo del capital, en las distintas zonas geográficas del sistema mundial capitalista, así como en las particularidades de las formaciones histórico-sociales. En consecuencia, no es a nivel de las abstracciones del modo de producción capitalista que se puede -o se debe- encontrar explicación a las particularidades de las estructuras de clase donde el campesinado se ha mantenido y ha jugado un rol en la reproducción del capital. En esta cuestión diferimos de muchos autores pertenecientes a la corriente estructuralista del marxismo, del ámbito internacional y latinoamericano, que planteaban esta idea en las décadas de 1970 y 1980 (Meillassoux, 1998; Philippe Rey et al., 1980; Gutelman, 1981; Díaz-Polanco, 1988; Roger Bartra, 1974, entre muchos otros). A ese nivel de abstracción -donde se seleccionan sólo los elementos fundamentales que permiten generar una explicación general-, su tendencia cierta a la descomposición en la medida que el capital se expande -como lo indican Marx, y luego, a principios del siglo XX, Lenin $(1972,1985)$ y Kautsky (1983) - es prácticamente todo lo que puede señalarse. La tarea de explicar la existencia del campesinado -en tanto forma socialreal y efectivamente existente-, en determinadas expresiones particulares de un capitalismo sui generis -como decía Marini (1979)-, corresponde a otro nivel de la teorización, más concreto: el del sistema mundial.

Sin duda, la manera en que lo plantean los autores clásicos resulta un poco tajante y categórica, pues se reduce a una ecuación simple: campesinado + capitalismo $=$ diferenciación, $\mathrm{y}$, sin dudas, la forma en que se desplegaron estos procesos en el mundo dependiente durante el siglo XX pone serias dificultades a una lectura literal de esa ecuación. A partir de esta misma observación histórica se generó un acalorado debate en América Latina durante los años en que la cuestión campesina era tema central en la región, desde fines de la década de 1960 hasta incluso principios de la de 1980. A partir de allí surge la llamada controversia entre campesinistas y descampesinistas, la cual no pretendemos abordar aquí, aunque resulta igualmente necesario referir a ciertos nodos del debate. ${ }^{12}$ Los descampesinistas, siguiendo a Lenin y Kaustky, se enfocaron en los procesos de descomposición y desaparición de las formas campesinas. Sus diagnósticos se basaban en la idea de que el campesinado tarde o temprano se disolvería. Por su parte, los campesinistas rechazaron fuertemente esas tesis y plantearon una funcionalidad, recreación e incluso fortalecimiento del campesinado en el contexto capitalista. Recuperaron fuertemente la figura de un historiador económico ruso, ligado al 
anarquismo -Alexander Vasillavich Chayanov-, el cual había roto con la tendencia del marxismo de analizar a los campesinos en tanto clase social, focalizando el análisis en su dimensión económica, creando el concepto de economía campesina, e intentando identificar la racionalidad que conduce la producción campesina. ${ }^{13}$

Pensamos que las dicotomías que plantea este debate no son necesariamente contradictorias. El hecho de que es una tendencia en el modo de producción capitalista que los campesinos sufran un proceso de diferenciación, ya sea con mayor tendencia a su proletarización o a su pequeño-aburguesamiento, es históricamente indiscutible. Prácticamente no existen países capitalistas centrales que cuenten a los campesinos entre sus estructuras agrarias. En ello, Marx, Lenin y Kautsky tienen la razón. Sin embargo, esto no quiere decir que el destino de los países dependientes sea seguir mecánicamente la senda de los desarrollados, pues ello supondría asumir una teoría evolucionista de la modernización al estilo de Rostow (1961). El capitalismo dependiente, como señala Marini (1979) es sui generis, y presenta deformaciones y particularidades. Una de esas deformaciones ha sido, en determinados momentos históricos, la incorporación de plustrabajo generado mediante relaciones productivas domésticas por diferentes mecanismos, según fueran los requerimientos delpatrón de reproducción del capital que operaba en esa zona y momento. Una lectura de Lenin y Kausky sin tomar en cuenta los mecanismos históricos de explotación y reproducción de esa explotación es ahistórica y dogmática. En ello, los descampesinistas se equivocaron.

Sin embargo -como hicieron algunos campesinistas chayanovistas- plantear que la persistencia del campesinado obedece a la dinámica propia de la producción campesina es, por lo bajo, un exceso de romanticismo; en efecto, la única forma de seguir sosteniendo una postura de ese tipo durante el actual patrón de reproducción de capital exportador es deformar y fetichizar la definición de campesinado, al punto de perder su sentido heurístico. La tendencia a la desaparición del campesinado como clase social en el modo de producción capitalista es una realidad histórica -en países centrales- y abstracta -en países dependientes-, lo que implica que cuando las necesidades específicas de la reproducción el capital en espacios dependientes los requieran, las presiones estructurales serán en el sentido de la recreación de esta clase, y viceversa: cuando la reproducción del capital requiera lo contrario, las presiones estructurales serán hacia su descomposición, y la resistencia del campesinado vendrá del lado de la clase para sí, de sus demandas políticas, antes que de una presunta lógica productiva indeterminada que lo aleje de las presiones del modo de producción en que se insertan. Algunos campesinistas (Warman, 1988; Stavenhagen, 1975) -inspirados por la teoría marxista de la dependencia- pudieron ver en esta funcionalización del campesinado de parte de una expresión histórica concreta del modo de producción capitalista, la causa de su persistencia en los contextos dependientes de los años de la industrialización sustitutiva de importaciones.

En el capitalismo los campesinos son productores de mercancías, y, como tales, no están del todo exentos de las reglas de la circulación capitalista. Pueden mercantilizar porciones variables de su producción doméstica, sin embargo, ello no los margina de las reglas de esa circulación. Esto no significa que no exista una "lógica" productiva distinta en el campesinado, por cierto, ésta existe, y es aquella que señaló Marx y que releva Chayanov: la unidad económica no busca la ganancia sino su subsistencia, y la producción se lleva a cabo mediante relaciones familiares, es decir, domésticas. La pregunta es si acaso esta lógica diferente es el origen de su condición de economía campesina inserta en la circulación capitalista, que no se transforma, o es más bien el resultado de la incapacidad de acumular de dicha unidad productiva, no debido a su propia lógica sino a las limitaciones en medios de producción y exacciones comerciales y tributarias, en un contexto donde el capital no tiene el dinamismo para proletarizar esa población. Pensamos que la respuesta es esta última. Cuando el campesinado logra tener acceso a medios de producción y condiciones de mercado que le permiten acumular, se desarrolla el proceso de diferenciación y la producción de mercancías detona las dinámicas que relevaron Lenin y Kautsky. La presunta lógica precapitalista es más bien una lógica subcapitalista.

Y este último punto es muy importante. Este campesinado latinoamericano, productor de mercancías y valores de uso de autoconsumo, que no contrata -o casi no contrata- mano de obra externa a la familia, no es ni histórica ni teóricamente una clase residual de modos de producción anteriores; no es un "fósil" del pasado, 
ni una forma productiva pretérita, por el contrario, es una clase social propia de determinadas condiciones históricas del capitalismo dependiente, sometida a un proceso de explotación, y que fue funcionalizada por las lógicas de reproducción del capital. Es una clase social que, por sus características de producción no capitalista, mantiene intercambios que suelen ser desiguales con su entorno capitalista, ya que vende su producción a precios que no contemplan la ganancia media (Bartra, 2007). De esta manera, "los campesinos modernos son por derecho propio y para su desgracia una clase del capitalismo" (Bartra, 2016, p. 182), pero, agregamos y destacamos, no del modo de producción capitalista, sino del capitalismo dependiente como forma histórica concreta de ese modo de producción en momentos y circunstancias históricas determinadas.

Este planteamiento nos posiciona en la vereda opuesta a una parte significativa de la recuperación contemporánea del debate campesinista-descampesinista (Diez y Kostlin, 2009). Se advierte en las relecturas recientes, una cierta tendencia -que está en sintonía con la hegemonía del culturalismo y sus raíces filosóficas románticas- a esencializar la particularidad campesina. Ello es lo que se aprecia cuando se plantea la persistencia del campesinado y paralelamente se relativiza aquello que el concepto ha designado - por ejemplo, al nominar por "campesinado" a un "objeto" que difiere del definido en las formulaciones originales- como es una "identidad campesina", igualmente válida como objeto de estudio, pero evidentemente diferente de la clase social (ver, por ejemplo a Figurelli, 2016, y Heredia, 2003). Esto ocurre también al adjudicar la persistencia de "racionalidades particulares" - desmarcadas de la dinámica y de la totalidad social a la que pertenecen (Ver, por ejemplo, a Landini, 2011)-- a la particularidad cultural, o a valores y a tradiciones. Esto lleva implícita la idea históricamente estática del campesinado como residuo del pasado. ${ }^{14}$

Yendo a lo concreto: ¿Existe diferenciación campesina en los contextos latinoamericanos (tanto en los años del debate, como hoy en día)? ¿Se encuentra o se ha encontrado el campesinado en vías de una trasformación cualitativa de su constitución como clase social? Son estas las interrogantes que deben responderse para comenzar a hablar, por ejemplo, de persistencia campesina.

Lo que la historia actual de la región muestra no es la inmutabilidad del campesinado, sino todo lo contrario, su relativa variabilidad frente a los contextos: su recreación y su descomposición según las necesidades de los patrones de reproducción de capital históricos (Cuevas, 2017, Warman, 1988; Stavenhagen, 1975). Una mirada a la estructura agraria de países que cuentan al campesinado como parte de su estructura de clases (como por ejemplo México) da cuenta de la existencia de un continuo entre las formas capitalistas y las domésticas de reproducción (Cuevas, 2017). Por lo tanto, aceptamos la idea de que existen formas transicionales entre campesinado y proletariado agrario, y pequeña burguesía agraria, aunque ello es a nivel de su reproducción, puesto que, en tanto análisis de clase, el examen político e histórico debe hilar más fino. Nuestra propuesta de tipificación de unidades domésticas pretende captar precisamente estos movimientos.

Lo central, pensamos, es establecer cuál es el tipo de relación social de producción que predomina en la reproducción de la UD, e intentar analizar sin dogmatismos si las formas transicionales se encuentran más próximas a relaciones de producción domésticas o capitalistas, lo que explica de qué manera opera la explotación del trabajo. Es determinando esa relación que podemos advertir cuál es la lógica rectora del sector social del que se habla. Lo anterior permite un análisis de la clase en sí. Y pensamos que un indicador respecto de qué tipo de relaciones predominan es la forma en que las UDs componen el ingreso que les permite reproducirse, lo cual es el fundamento de establecer una tipología de UDs en función de la proporción de distintos tipos de fuentes de ingreso -que representan los tipos de relaciones productivas- en el ingreso total que reproduce a las UDs. Dicho análisis es limitado, sin embargo, permite avanzar hacia conclusiones importantes respecto de las formas de explotación del trabajo en el sector agropecuario, tanto en patrones de reproducción de capital históricos previos como en el actual. No pretende ser un análisis que corra en paralelo al de la case social, sino, más bien, un análisis al interior de dicha categoría. No pretende crear una categoría análoga a la de clase social, ni menos un divorcio entre la dimensión económica y la política, sólo plantea la necesidad de reconocer la realidad de las transformaciones de las clases que en el agro -parafraseando a 
Antunes (2005) - viven de su trabajo. En tanto definición teórica, esta propuesta se encuentra en el nivel de abstracción del capitalismo dependiente, y debe ser histórica y políticamente particularizada.

\section{La TiPología de Unidades Domésticas}

Finalmente, como conclusión de esta propuesta se expone a continuación la tipología de UDs derivada de los elementos previamente discutidos. Identificamos cuatro fuentes de ingreso de la unidad doméstica, cuya proporción determina el tipo de UD. Estos son: A = Producción doméstica auto-consumida (valores de uso) $\mathrm{M}^{\prime}=$ Producción doméstica mercantilizada, ${ }^{15} \mathrm{MT}=$ Mercancía Trabajo (tiempo de trabajo vendido al capital, bajo la forma de salarios), que puede ser de carácter permanente o temporal, y $S=$ Subsidios. Las tres primeras representan relaciones de producción: la producción doméstica autoconsumida representa relaciones productivas domésticas; la producción doméstica mercantilizada puede corresponder a relaciones capital-trabajo desde el lado del capital o a relaciones productivas domésticas, y mercancía trabajo a la relación capital trabajo desde el lado del trabajo. Debe aclararse que, al tratarse de unidades compuestas por más de un trabajador, cada fuente (A, M', MT o S) puede ser producto de la suma de los aportes de más de un integrante, y un integrante puede aportar ingresos de más de una fuente. ${ }^{16}$ Como se indicó, estos tipos se establecen a partir de las proporciones de ingresos provenientes de las distintas fuentes, establecidas en la tabla 1.

La tipología reconoce a tres grandes tipos generales de UDs: las productoras agropecuarias, las subsidiadas y las proletarias. Dentro de cada uno de estos grupos la composición clasista es heterogénea. Las unidades proletariasno presentan subdivisiones. Su identificación de clase es claramente el proletariado agropecuario.

Sin embargo, en las unidades agropecuarias y en las subsidiadas reconocemos subtipos. Las unidades subsidiadas son un tipo creado para capturar a las unidades que ya no viven de los aportes de su trabajo actual-y que usualmente responden a unidades que pertenecieron a otros tipos, que ya se encuentran en fases terminales de su ciclo demográfico. En ellas se reconocen tres subtipos, (agropecuarias, proletarizadas y no trabajadoras).

En las unidades agropecuarias, reconocemos dos subtipos: las no proletarias y las semiproletarias. Ambos grupos tienen una identificación de clase heterogénea. Las no proletarias, se dividen a su vez en dos subsubtipos: comerciales y campesinas. Entre ellas hay identificaciones de clase diferentes, pues, mientras las comerciales pertenecen a la burguesía o pequeña burguesía, las campesinas pertenecen -valga la redundanciaal campesinado. Por su parte, las unidades semiproletarias se dividen entre las comerciales, que podrían adscribirse, según los casos, al proletariado y a la burguesía, y las de autoconsumo, que podrían adscribirse, según los casos, al campesinado y al proletariado.

El perfil general derivado del peso proporcional de los diferentes tipos de UDs en el conjunto de unidades domésticas agropecuarias conforma una estructura de unidades domésticas, caracterizada por la preeminencia de uno o más tipos específicos entre el conjunto de las unidades, lo que tiene efectos importantes a nivel del mercado de trabajo, a nivel de los tipos de producción, etc. El concepto de estructura de UDs es diferente al tradicional concepto de estructura agraria, y no pretende reemplazarlo, sino que estudia otra dimensión de la estructura del sector -la reproductiva-, es decir, es más bien complementario. 
TABLA 1:

Construcción de la tipología de las Unidades Domésticas a partir de la composición de su ingreso

\begin{tabular}{|c|c|c|c|c|c|c|c|c|}
\hline * & \multicolumn{4}{|c|}{ UD productoras agropecuarias } & \multicolumn{3}{|c|}{ UD subsidiadas } & \multirow{5}{*}{$\begin{array}{l}\frac{9}{0} \\
\frac{\pi}{2} \\
\frac{\pi}{\pi} \\
\frac{0}{0} \\
0 \\
\frac{0}{2} \\
0 \\
0\end{array}$} \\
\hline Fórmula & & $\left.M^{\prime}+A\right)>$ & $(\overline{U T+S}))^{* * * *}$ & & & $A+M^{\prime}+N$ & & \\
\hline ** & no pro & tarias & semipr & etarias & \multirow[b]{3}{*}{ 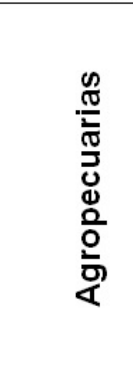 } & \multirow[b]{3}{*}{ 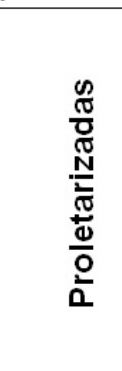 } & \multirow[b]{3}{*}{ 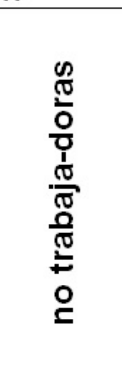 } & \\
\hline Fórmula & \multicolumn{2}{|c|}{$(\mathrm{MT}=0)$} & \multicolumn{2}{|c|}{$(\mathrm{MT}>0)$} & & & & \\
\hline$\star * * *$ & 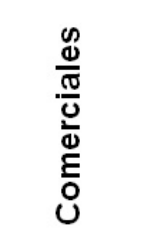 & 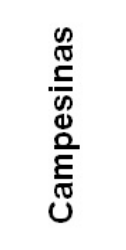 & 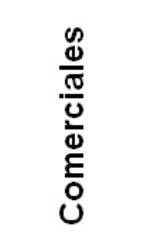 & 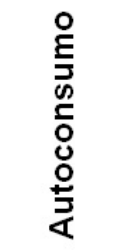 & & & & \\
\hline Fórmula & $\left(M^{\prime}>A\right)$ & $\left(A>M^{\prime}\right)$ & $\left(M^{\prime}>A\right)$ & $\left(A>M^{\prime}\right)$ & $\begin{array}{c}\left(A+M{ }^{\prime}>\right. \\
M T)\end{array}$ & $\begin{array}{l}(\mathrm{MT}> \\
\mathrm{A}+\mathrm{M})\end{array}$ & $\begin{array}{l}(\mathrm{MT}= \\
\mathrm{A}+\mathrm{M})\end{array}$ & $\begin{array}{c}\text { MT > } \\
\text { A+M'+ } \\
S\end{array}$ \\
\hline \multicolumn{2}{|c|}{$\begin{array}{l}{ }^{\star T} \text { Tipo general } \\
{ }^{*} \text { Subtipo } \\
{ }^{* \star *} \text { Sub-Subtipo }\end{array}$} & \multicolumn{7}{|c|}{$\begin{array}{c}{ }^{* \star * *} \text { Donde: } \mathrm{A}=\text { Producción doméstica auto-consumida } \\
\mathrm{M}^{\prime}=\text { Producción doméstica mercantilizada } \\
\text { MT = Mercancía Trabajo } \\
\mathrm{S}=\text { Subsidios }\end{array}$} \\
\hline
\end{tabular}

Fuente: elaboración propia

TABLA 2

Resumen de la Tipología de las Unidades Domésticas a partir de la composición de su ingreso

\begin{tabular}{|c|c|c|c|c|}
\hline Tipo General & Subtipo & Sub-Subtipo & $\begin{array}{l}\text { Resumen } \\
\text { fórmula }\end{array}$ & $\begin{array}{l}\text { Características } \\
\text { generales }\end{array}$ \\
\hline \multirow[t]{4}{*}{$\begin{array}{l}\text { Productoras } \\
\text { agropecuarias }\end{array}$} & \multirow[t]{2}{*}{ No proletarias } & Comerciales & \begin{tabular}{lr|}
$\left(\mathrm{M}^{\prime}+\mathrm{A}\right)$ & $>$ \\
$(\mathrm{MT}+\mathrm{S}))$ & $\&$ \\
$(\mathrm{MT}=0) \&\left(\mathrm{M}^{\prime}\right.$ \\
$>\mathrm{A})$
\end{tabular} & $\begin{array}{l}\text { Capitalistas (tipo farmer) } \\
\text { sin salarios }\end{array}$ \\
\hline & & Campesinas & $\begin{array}{lr}\left(\left(M^{\prime}+A\right)\right. & > \\
(M T+S)) \quad \& \\
(M T=0) \&(A> \\
\left.M^{\prime}\right)\end{array}$ & $\begin{array}{l}\text { No capitalistas, sin } \\
\text { salarios }\end{array}$ \\
\hline & \multirow[t]{2}{*}{ Semiproletarias } & Comerciales & \begin{tabular}{lr|}
$\left(\left(\mathrm{M}^{\prime}+\mathrm{A}\right)\right.$ & $>$ \\
$(\mathrm{MT}+\mathrm{S})) \quad \&$ \\
$(\mathrm{MT}>0)$
\end{tabular} & $\begin{array}{l}\text { Productivamente } \\
\text { capitalistas y con } \\
\text { miembros asalariados }\end{array}$ \\
\hline & & Autoconsumo & $\begin{array}{lr}\left(\left(M^{\prime}+\mathrm{A}\right)\right. & > \\
(\mathrm{MT}+\mathrm{S})) \quad \& \\
(\mathrm{MT}>0) \&(\mathrm{~A}> \\
\left.\mathrm{M}^{\prime}\right)\end{array}$ & $\begin{array}{l}\text { Productivamente r no } \\
\text { capitalistas y con } \\
\text { miembros asalariados }\end{array}$ \\
\hline \multirow[t]{3}{*}{ Subsidiadas } & & Agropecuarias & $\begin{array}{l}\left.\left(\mathrm{S}+\mathrm{M}^{\prime}+\mathrm{MT}\right)\right) \\
\left(\mathrm{A}+\mathrm{M}^{\prime}>\mathrm{MT}\right) \\
\end{array}$ & $\begin{array}{l}\text { Subsidiadas, producción } \\
\text { doméstica más } \\
\text { importante que salario }\end{array}$ \\
\hline & & Proletarizadas & $\begin{array}{l}(\mathrm{S} \\
\left.\left(\mathrm{A}+\mathrm{M}^{\prime}+\mathrm{MT}\right)\right) \\
\&(\mathrm{MT}>\mathrm{A}+\mathrm{M})\end{array}$ & $\begin{array}{l}\text { Subsidiadas, salarios } \\
\text { más importantes que } \\
\text { producción doméstica. }\end{array}$ \\
\hline & & No trabajadoras & $\begin{array}{l}(\mathrm{S} \\
\left(\mathrm{A}+\mathrm{M}^{\prime}+\mathrm{MT}\right. \\
\&(\mathrm{MT}=\mathrm{A}+\mathrm{M})\end{array}$ & $\begin{array}{l}\text { No se inclinan ni por } \\
\text { asalariadas ni proletarias } \\
\text { porque estas fuentes son } \\
\text { menores o inexistentes }\end{array}$ \\
\hline Proletarias & & Proletarias & $\mathrm{MT}>\mathrm{A}+\mathrm{M}^{\prime}+\mathrm{S}$ & $\begin{array}{l}\text { Son principalmente } \\
\text { asalariadas, y otros } \\
\text { aportes son secundarios }\end{array}$ \\
\hline \multicolumn{5}{|c|}{$\begin{array}{l}\text { "Donde: } \quad \text { A = Producción doméstica auteconsumida } \\
\text { M' = Producción doméstica mercantilizada } \\
\text { MT = Mercancía Trabajo } \\
\text { S = Subsidios }\end{array}$} \\
\hline
\end{tabular}




\section{Bibliografía}

Antunes, R. (2005). Los sentidos del trabajo. Buenos Aires: Herramienta-TEL

Atria, R. (2004). Estructura ocupacional, estructura social y clases sociales. Politicas Sociales, 96, Disponible en: https: //repositorio.cepal.org/bitstream/handle/11362/6087/S049713_es.pdf?sequence=1\&isAllowed=y

Balazote, A., Rádovich, J., Rotman, M., y Trinchero, H. (1998). La economía doméstica: novedades del sujeto económico. H. Trinchero, (Editor). Antropología económica: Ficciones y producciones del hombre económico. Buenos Aires: EUDEBA

Bartra, R. (1974). Estructura agraria y clases sociales en México. México: Era

Bartra, A. (2007). La explotación del trabajo campesino por el capital. En El capital en su laberinto, 193-280. México: Ítaca

Bartra, A. (2016). Hacia un marxismo mundano: La clave está en los bordes. México: Itaca / UAM.

CEPAL (1989). Agricultura campesina y agricultura empresarial. Tipología de productores del agro mexicano. México: Siglo XXI

Chayanov, A.V. (1979). La organización de la unidad económica campesina: introducción. Plaza, O. (comp.) Economia Campesina. Lima: DESCO

Constantino, A., y Cantamutto, F, (2014). Patrón de reproducción del capital y clases sociales en la Argentina contemporánea. Sociológica, 29(81), 39-86.

Cuevas, P. (2017). La "ventaja" del asalariado rural latinoamericano: el trabajo silvoagropecuario en el actual patrón de acumulación de capital a través de los casos de Chile y México (Tesis doctoral). México: UNAM. Disponible en: http://oreon.dgbiblio.unam.mx/F/J2P95AC5DI8NEU76PCCF221R8BRERFS9FMXAIQYEASVHBE $7 \mathrm{H} 3 \mathrm{M}-27262$ ?func $=$ full-set-set\&set_number $=020085 \&$ set_entry $=000002 \&$ format $=999$

Díaz-Polanco, H. (1988). Teoría Marxista de la economía campesina. México: Juan Pablos Editor.

Diez, C., y Kostlin, L. (2009). Persistencia y cambio del campesinado. Un abordaje crítico a "La morada de la vida" desde el marxismo contemporáneo. Mundo Agrario, 10(19). https://www.mundoagrario.unlp.edu.ar/article/v iew/v10n19a07/618

Dos Santos, T. (1983). El concepto de clases sociales. Bagu, S (Coord.) Teoría Marxista de las clases sociales, 91-118. México: UAM-I.

Figurelli, M. (2016). Alimentación, vida y naturaleza: La construcción de lo campesino entre movimientos populares agrarios. Mundo Agrario, 17(36), Recuperado de http://www.mundoagrario.unlp.edu.ar/article/view/MAe037

Frank, A. (1970). Capitalismo y subdesarrollo en América Latina. Buenos Aires: Siglo XXI.

Gordillo, G. (1992). Procesos de subsunción del trabajo al capital en el capitalismo periférico. H. Trinchero (comp.), Antropología Económica vol. II. Buenos Aires: Centro Editor de América Latina.

Gutelman, M. (1981). Estructuras y reformas agrarias. Los problemas agrarios y los métodos para su estudio. Barcelona: Fontamara

Harris, O. (1986). La unidad doméstica como una unidad natura. Nueva Antropología, VIII(30), 199-222

Heredia, B. (2003). La morada de la vida. Trabajo familiar de pequeños productores del nordeste de Brasil. Buenos Aires: La Colmena.

Heynig, K. (1982). Principales enfoques sobre la economía campesina. Revista de la CEPAL, 16.

Kautsky, K. (1983). La cuestión agraria. México: Siglo XXI.

Kay, C. (2007). Algunas reflexiones sobre los estudios rurales en América latina. Iconos. Revista de Ciencias Sociales, 29, 31-50.

Kay, C. (2009). Estudios rurales en América Latina en el periodo de globalización neoliberal: ¿una nueva ruralidad?. Revista Mexicana de Sociología, 71(4), 607-645.

Landini, F. (2011). Racionalidad económica campesina. Mundo Agrario, 12(23), http://www.mundoagrario.unlp.ed u.ar/ 
Lenin, V. I. (1961). Una Gran Iniciativa. En Lenin. Obras escogidas en tres volúmenes, vol. 3 118-129. Moscú: Progreso. Lenin, V. I. (1972). El desarrollo del capitalismo en Rusia. Santiago de Chile: Quimantú

Lenin, V. I. (1985). Nuevos datos sobre las leyes del desarrollo del capitalismo en la agricultura. En Obras Completas, Tomo 27. Moscú: Editorial Progreso, 135-238

Llambí, L., y Pérez, E. (2007). Nuevas ruralidades y viejos campesinismos. Agenda para una nueva sociología rural latinoamericana. Cuadernos de Desarrollo Rural, 059, 37-61.

Marini, R. (1979). Dialéctica de la dependencia. México: Ediciones Era.

Marx, C. (1968). El Capital (Tomo I, II y III). México: Fondo de Cultura Económica.

Marx, K. (1986). El Capital. Tomo III/Vol. 8. México: Siglo XXI.

Meillassoux, C. (1998). Mujeres, graneros y capitales. México: Siglo XIX.

Olin Wright, E. (1983). Clase, crisis y Estado. Madrid: Siglo XXI

Osorio, J. (1987). El análisis de coyuntura. México: CIDAMO

Osorio, J. (2001). Fundamentos del análisis social. La realidad social y su conocimiento. México: Fondo de Cultura Económica.

Osorio, J. (2004). Critica de la economía vulgar Reproducción del capital y dependencia. México: Miguel Ángel Porrua.

Osorio, J. (2009). Explotación redoblada y actualidad de la revolución: refundación societal, rearticulación popular y nuevo autoritarismo. México: ITACA, UAM-X.

Osorio, J. (2009 b). El Estado en el centro de la mundialización: La sociedad civil y el asunto del poder. México: FCE - UAM-X

Osorio, J. (2012). Estado, biopoder y exclusión. Análisis desde la lógica del capital. Barcelona: México: Antropos - UAM$\mathrm{X}$

Osorio, J. (2014). Estado, reproducción de capital y lucha de clases. La unidad económico/politica del capital. México: IIEc-UNAM

Osorio, J. (2016). Teoria marxista de la dependencia. México: UAM-X - Itaca

Palerm, A. (2008). Antropología y Marxismo. México: CIESAS - UAM- U. Iberoamericana

Pérez Soto, C. (2008). Desde Hegel. Para una crítica radical de las ciencias sociales. México: Itaca.

Philippe Rey, P., Michel, E., y Samuel, M. (1980). El proceso de proletarización de los campesinos. México: Terra Nova

Poulantzas, N. (1979). Las clases sociales en el capitalismo actual. México: Siglo XXI

Ratier, H. (2002). Rural, ruralidad, nueva ruralidad y contraurbanización. Un estado de la cuestión. Revista de Ciencias Humanas, 31, 9-29

Rosati, G., y Donaire, R. (2012). Sobre el supuesto de 'homogeneidad' en el análisis de la estructura social. Reflexiones a partir de un ejercicio empírico. Entramados y perspectivas, 2(2), 71-98.

Rostow, W. (1961). Las etapas del crecimiento económico. México: Fondo de Cultura económica.

Rubio, B. (2001). Explotadosy Excluidos: Los campesinos latinoamericanos en la fase agroexportadora neoliberal. México: Plaza y Valdés editores.

Rubio, B. (2002). La exclusión de los campesinos y las nuevas corrientes teóricas de interpretación. Nueva Sociedad, 182, 21-33. http://www.nuso.org/upload/articulos/3085_1.pdf

Sahlins, M. (1977). Economia de la edad de piedra. Madrid: Akal.

Stavenhagen, R. (1975). Capitalismo y campesinado en el desarrollo agrario. Investigación Económica, 34(136), 663-676.

Stoler, A. (1987). Transiciones en Sumatra: el capitalismo colonial y las teorías sobre la subsunción. Revista Internacional de Ciencias Sociales, 114, 103- 124.

Wallerstein, I. (2004). Capitalismo histórico y movimientos antisistémicos. Un análisis de Sistemas-Mundo. Madrid: Akal.

Warman, A.(1988). Los campesinos hijos predilectos del régimen. México: Editorial Nuestro Tiempo 
Weber, M. (1964). Economía y sociedad. México: Fondo de Cultura Económica.

\section{Notas}

1 La propuesta teórico-metodológica aquí presentada es parte de una investigación mayor (Cuevas, 2017); es aplicada sobre dos bases de datos de encuestas nacionales de hogares, de manera comparativa entre Chile y México. En el presente artículo sólo se expone la propuesta, sin su aplicación.

2 Durante el tercer cuarto del siglo XX toma fuerza la tesis que plantea que la presencia del campesinado en una estructura agraria reduce los costos salariales de los capitales que operan en el agro comprando fuerza de trabajo, dado que la economía campesina "subsidiaría” el diferencial de salarios. Esta tesis, sostenida de manera icónica por Bartra (2007) entre varios otros autores- se sustentaba en la idea de que el capitalismo latinoamericano consistía en una configuración particular de un capitalismo -dependiente- que integraba funcionalmente características modernas y premodernas en función de los requerimientos de la acumulación mundial y local (Frank, 1970; Marini, 1979).

3 La presente propuesta plantea de idea de la clase social restringiéndola a su sentido de clase en si -grupos sociales aunados de hecho por las relaciones sociales que establecen para producir su existencia- y no necesariamente de la clase para si -conciencia colectiva y de acción conjunta de esos grupos como sujeto histórico-, cuestión de vital importancia que surge en un análisis con un mayor de nivel de concreción histórica. No concordamos acá con la tendencia a suponer que la falta de correlación entre clase en si y para sí en una situación histórica concreta invalida el análisis de clases. Ello es materia de un análisis histórico concreto.

4 Llambí y Pérez (2007) señalan como rasgos característicos de la concepción clásica de ruralidad, una baja densidad demográfica, el predominio de la agricultura en la estructura productiva de una localidad o región, y unos rasgos culturales diferentes a los que caracterizan a la población de las grandes ciudades.

5 Entre los autores más radicales de esta tendencia (Por ejemplo Bryan Mills, Terry Marsden, entre otros) se niega la posibilidad de definir lo rural, señalando que ésta sería un muy buen ejemplo de aquello que los posmodernos han llamado hiper-realidad, es decir, algo cuya existencia es virtual y cuyo poder explicativo es dudoso, es decir, una construcción cultural (Ratier, 2002).

6 El concepto de patrón reproducción capital permite caracterizar la reproducción del capital en tiempos históricos y espacios geográficos determinados, de acuerdo a los distintos sectores o ramas que el capital privilegia (Osorio 2004, 2009) y la forma concreta que asume el ciclo del capital.

7 Tanto la desagrarización como la pluriactividad serían consecuencias y expresiones de una reacomodación nacional e internacional entre sectores de la economía, con expresiones diferenciadas en los países centrales y los países dependientes. En nuestra región, por ejemplo, tal y como señala Kay (2007), y como veremos, “...para la mayoría de los campesinos su creciente participación en actividades no-agropecuarias obedece a su crisis de reproducción y tales actividades sólo les permiten la sobrevivencia...”(Kay, 2007, p. 33).

8 El proceso de abstracción presenta niveles y estadios, dado que responde al método dialéctico de separación e integración de la realidad con fines de conocimiento. "Los estadios más abstractos, ponen énfasis en los factores matrices de la organización social. (....) Los niveles menos abstractos, por el contrario, ponen su acento en la riqueza de elementos que presenta la realidad en su cercanía, buscando rescatar al mismo tiempo su diversidad y singularidad" (Osorio, 1987, p. 41). Por medio de la distinción de estos niveles se persigue desarrollar la investigación en un nivel teórico respecto de elementos que no existen de manera pura en la realidad empírica, pero que, al seleccionarlos, se da cuenta de las relaciones fundamentales que subyacen a esa realidad. "En seguida el método busca reintegrar progresivamente los otros aspectos de la realidad y aproximarse a lo concreto" (Dos Santos, 1983, pp. 32).

9 En efecto, el mismo Marx aclara que, ni siquiera en Inglaterra -expresión más "pura” del capitalismo por los años en que escribe- “...se destaca con pureza esa articulación de clases” y en seguida explica que también allí “...grados intermedios y de transición (aunque incomparablemente menos en el campo que en la ciudades) encubren por doquier las líneas de demarcación” (Marx, 1986, p. 1123), lo que implica que, al acercarse a un nivel de concreción mayor, debe complejizarse el análisis de las clases en su aproximación a la historia.

10 Como han destacado algunos estudios (Balazote, Rádovich, Rotman y Trinchero, 1998), la economía neoclásica, con su particular interés por modelizar el comportamiento de los individuos, parte de la premisa de un orden de preferencias individuales, ante lo cual, un "proceso decisional” ocurrido al interior del grupo doméstico sería una dificultad metodológica. Ante esta dificultad, durante la década de 1990, y luego de un premio Nobel de Economía en el campo de la "economía familiar" -Gary Stanley Becker, en 1992- esta escuela de economía ortodoxa se abrió a abordar el problema de la economía doméstica, mediante dos estrategias, la primera es adoptar una serie de supuestos que permitirían operar como si la unidad doméstica fuera un individuo racional, y una más compleja, en el campo de la utilización de la teoría de juegos. 
11 El método de concretización progresiva supone, como se señaló más atrás, una aproximación gradual desde lo abstracto a lo concreto y viceversa. Osorio (2004) reconoce analíticamente cuatro niveles o estadios de abstracción en el análisis de la realidad social, desde el más abstracto al más concreto: modo de producción, sistema mundial, formación económicosocial y coyuntura.

12 Presentarlo de esta manera es sólo una aproximación esquemática inspirada en la forma que lo han expuesto autores como Heynig (1982), y con más matices teóricos: CEPAL (1989), entre otros.

13 Chayanov plantea una verdadera teoría del funcionamiento interno de la economía campesina; Le interesa “...tan sólo la mecánica del proceso organizativo de la unidad económica campesina y no el desarrollo del sistema y de sus formas de organización” (Chayanov, 1979, p. 97), es decir, la separa de su contenido clasista. En consecuencia, con esto el punto central del análisis lo constituye la unidad familiar como unidad elemental de producción y consumo. En términos muy sintéticos, la propuesta de Chayanov plantea que la racionalidad que conduce la producción campesina es aquella que busca la satisfacción de las necesidades de subsistencia de la unidad campesina y no el incremento de la ganancia. Las decisiones económicas de la unidad familiar consideran en forma inseparable la producción y el consumo final de la familia.

14 De ninguna manera lo señalado implica un rechazo al análisis cultural del campesinado ni de sus formas simbólicas y de adscripción identitaria a una categoría colectiva determinada. La crítica se dirige más bien a aquellos análisis en cuya mecánica se encuentra una lógica determinista cultural, que suponen la capacidad de una racionalidad de emerger y determinar a la totalidad social desvinculándola de su contexto de operación y evolución en sus relaciones.

15 Refiere a mercancías de origen agropecuario o de elaboración estrictamente doméstica; quedan excluidas las actividades comerciales de otro tipo y de venta de servicios.

16 Por ello, debe considerarse que, por ejemplo, MT puede ser igual a MT_integrante $1+\mathrm{MT}$ integrante2, y que S puede ser igual a $S \_$integrante $1+S \_$integrante2. 